\title{
Impact of Induced Normothermia on Occurrence of Post Anesthetic Shivering and Wound Infection among Patients Undergoing Abdominal Surgeries
}

\author{
Soad Abdeltwab Qurany Abdeltwab ${ }^{1}$, Hanaa Youssry Hashem², \\ Asmaa Diab Abdel Fattah Hassan ${ }^{3}$ and Heba Omer Ahmed ${ }^{4}$ \\ ${ }^{1}$ Demonstrator of Medical Surgical Nursing, \\ ${ }^{2}$ Assist. Prof. of Medical Surgical Nursing \\ ${ }^{3}$ Lecturer of Medical Surgical Nursing, \\ ${ }^{4}$ Lecturer of anesthesia surgical ICU and pain management \\ ${ }_{1,2,3}$ Medical surgical nursing department, Faculty of Nursing-Cairo University-Egypt \\ ${ }^{4}$ Anesthesia, surgical ICU and pain management department, Faculty of Medicine Cairo University- Egypt
}

\begin{abstract}
Many complications can be developed as a result of intraoperative hypothermia including postanesthesia shivering and wound infection, Therefore the aim of the current study was to evaluate the impact of induced normothermia on occurrence of post anesthetic shivering and wound infection among patients undergoing abdominal surgeries. A convenient sample consists of 60 adult male and female patients who was undergo abdominal surgery (hernia repair except inguinal hernia repair, open cholecystectomy) at one of the university hospitals in Cairo governorate was recruited to fulfill the aim. A quasi-experimental design (posttest control group design) was utilized to achieve the aim of the present study by using tool s I, Demographic and medical data Questioner II, Bedside shivering assessment scale (BSAS) III, Asepsis wound scoring system. The study result revealed that $70 \%$ of control group complain from hypothermia after 90 minute of anesthesia induction with mean $\left(35.47^{\circ} \mathrm{C} \pm 761^{\circ} \mathrm{C}\right)$. The current study revealed that the use of warm fluid is effective in keeping patient warmed in operation less than two hours with $p$ value $=.000$. Study (warmed) group have less occurrence and severity of post anesthesia shivering with $p=$ .016 and wound infection with $p=.035$.
\end{abstract}

Key words: intraoperative hypothermia, post anesthetic shivering, wound infection and abdominal surgeries.

\section{Introduction}

Unplanned intra operative hypothermia is one of the most common complication that face patients during their surgical operation it represent about $74 \%$ and it can have serious health-related and financial consequences [1].The normal core body temperature is between $36.50^{\circ} \mathrm{C}$ and $37.50^{\circ} \mathrm{C}$, unplanned perioperative hypothermia defined as a core body temperature of less than $36.0^{\circ} \mathrm{C}\left(96.8^{\circ} \mathrm{F}\right)$ Regular measurement and recording of temperature is the key to prompt identification of hypothermia and its management [1].

Body temperature management is one of homeostasis mechanisms, human body maintain core temperature within certain limits by balance between heat production and heat loss. Body produces heat by increase metabolic rate, increase physical activity and thermogenesis which mainly occur by the shivering. Heat loss in the intra operative period occurs mainly by radiation, convection, conduction and evaporation, radiation represents about $40 \%$ to $60 \%$ from heat loss in the operating room, convection represent about $25 \%$ to $50 \%$ from heat loss in the operating room. Conduction represents about $10 \%$ from heat loss in the operating room, evaporation accounts about $25 \%$ from heat loss in the operating room [2].

All patients, regardless of age or gender, are at risk for developing intra operative hypothermia when general anesthesia or regional anesthesia is involved. Even the patient is normothermic prior to surgery; the body core temperature can drop $1-2^{\circ} \mathrm{C}$ within thirty minutes of receiving anesthesia. Anesthesia causes vasodilation, allowing the warm blood from the body's core to redistribute to the peripheral extremities. This phenomenon is also as redistribution temperature drop and is known as a common risk of anesthesia [3].

Fluid is usually administered to patients experiencing day-case and short duration surgery because it has been demonstrated that 1 liter fluid lead to an improved patient recovery. A mathematical calculation revealed that the administration of a liter of crystalloid fluid at room temperature results in decrease in core temperature of around $0.25^{\circ} \mathrm{C}$ in an average $(70-\mathrm{kg})$ individual. Higher postoperative core temperatures and a lower frequency of peri-operative hypothermia result from administration of 1 liter warmed fluid to patients having short duration general anesthesia [4].

Unplanned perioperative hypothermia is linked to several postsurgical morbidities such as impaired wound healing, surgical site infections, altered drug metabolism, cardiovascular effects, and increased 
respiratory distress. In addition, unintended perioperative hypothermia can lead to immediate postoperative complications such as blood loss, hypoxia, cardiac arrhythmias, shivering, and delayed ex-tubation [5].

Perianesthesia nurses remain challenged with keeping patients warm before, during, and after surgery. The ability to promote normal thermal balance in surgical patients requires a team effort. Using best evidence to guide clinical practices aimed at promoting thermal balance in the surgery patient is critical to provide of safe, quality care [6].

\section{Material And Methods}

The aim of the study was to evaluate the impact of induced normothermia on occurrence of post anesthetic shivering and wound infection among patients undergoing abdominal surgeries, to achieve this aim the following research hypothesis was formulated:

H1. Patients who will receive intraoperative warmed fluids will have normal intraoperative body temperature than patients who will not receive warmed fluid.

H2. Patients who will have normothermia will have less postoperative shivering score than patients who will have hypothermia.

H3. Patients who will have normothermia will have less incidence of SSI than patients who will be have hypothermia.

\subsection{Design}

A quasi-experimental design (posttest control group design) was utilized in the current study. It is an empirical study used to estimate the causal impact of an intervention on its target population. Quasiexperimental research shares similarities with the traditional experimental design or randomized controlled trial, but they specifically lack the element of random assignment to treatment or control. Instead, quasi-experimental designs typically allow the researcher to control the assignment to the treatment condition, but using some criterion other than random assignment [7].

\subsection{Setting}

The current study was conducted at general surgical wards $(11,25,27$ and 30) and general surgical operating rooms ( $2^{\text {nd }}$ and $3^{\text {rd }}$ floor) at El-manial University hospital.

\subsection{Sample:}

A convenient sample consists of 60 adult male and female patients who undergo abdominal surgery (hernia repair, open cholecystectomy) was recruited for this study. Patients were received general anesthesia and prophylactic antibiotic.

The following exclusion criteria were considered:

- Patients who received corticosteroids or other immunosuppressive drugs during the four weeks before surgery.

- Fever, infection, or both within one weak preoperatively.

- Patient was suffering from serious malnutrition (serum albumin, less than $3.3 \mathrm{~g}$ per deciliter, a white-cell count below 2500 cells per milliliter, or the loss of more than 20 percent of body weight).

- Patient with chronic disease e.g. cardiovascular diseases. Diabetes mellitus, hypertension, liver diseases, renal diseases...

- Duration of operation more than two hours.

\subsection{Data collection tools:}

The study was collected by using the following tool as follows:-

2.4.1. Demographic and medical data Questioner: It was developed by the investigator. This tool was consisted of two parts

Part I include: demographic data covering questions such as age, gender, level of education, occupation marital status .....etc. and

Part II include: Medical data sheet which include questions related to medical diagnosis, surgical intervention, duration of operation, body temperature measurements .....etc

2.4.2Bedside shivering assessment scale (BSAS);BSAS is standardized tool developed by Oslon, Grissom, Williamson, Bennett, Bellows, James; it is a 4-level tool while uses observation and palpation to score shivering. The BSAS requires raters to observe the patient for 2 minutes; this includes visual inspection as well as palpating the neck, thorax, arms, and legs. BSAS includes degree of shivering from 0 (none) which indicate 
no shivering to 3 (severe) which indicate severe shivering involve gross movements of the trunk and upper and lower extremities. The BSAS has adequate interrater reliability to be considered for use (kappa of 0.66.)

2.4.2Asepsis wound scoring system: It's a quantitative scoring method that provides a numerical score related to the severity of wound infection using objective criteria based on wound appearance and the clinical consequences of the infection. In which the score is calculated by sum of points assigned to the following factors: the duration of antibiotic administration, the drainage of pus during local anesthesia, the débridement of the wound during general anesthesia, the presence of a serous discharge, the presence of erythema, the presence of a purulent exudate, the separation of deep tissues, the isolation of bacteria from fluid discharged from the wound, and a duration of hospitalization exceeding 14 days. Scores exceeding 20 on this scale indicate wound infection. ASEPSIS system was reported an interrater reliability of 0.96 in patients having general surgery $[8,9]$.

\subsection{Pilot study}

A pilot study was conducted on $10 \%$ of the sample to evaluate clarity, applicability, and feasibility of the study. The modification was developed according to the results of the pilot study .

\subsection{Ethical considerations}

Primary approval was obtained from the research ethical committee of Faculty of Nursing. Also an official permission was obtained from hospital administrators to conduct the study. Each patient was informed about the purpose, nature and significance of the study. Each eligible subject who agreed to participate in the study was asked to sign a written informed consent form. Anonymity and confidentiality of study subject was assured through coding the data. Every participant has the right to withdraw from the study at any time; subjects were assured that this data was not be reused in another research without permission.

\subsection{Procedure for data collection:}

Once permission to conduct the current study was obtained from the appropriate authoritative personnel of the general surgeries OR and surgical wards, the investigator was initiate data collection. Names of subjects who were admitted to the general surgeries department and proper to the study subject was obtained from the surgeon and the head nurse of operating rooms. The study is conducted through three phases .

First phase is assessment phase during which the study participants was interviewed individually to explain the nature and purpose of the current study. Demographic and medical data was gathered and patient body temperature was assessed by tympanic temperature reading by using electronic thermometer .

Second phase is intervention phase which is which was implemented in the general surgical OR; in the intra operative period which started with anesthesia induction and end with patient discharge to recovery room. Patient was warmed through warmed IV fluids (isotonic solutions), irrigation fluids, and warmed blood if ordered by surgeon by using blood warmer machine to $37^{\circ} \mathrm{C}$ (in line warming machine).

In the last phase (evaluation phase) in the operating room patient body temperature was monitored using tympanic temperature reading every half hour. After the patient was discharged from the operating room to recovery room the patient body temperature measured using tympanic temperature reading, and patient body shivering was assessed using (BSAS) . finally within 2 weeks after operation wound infection is assessed using wound assessment tool (Asepsis scoring system).

2.8. Statistical analysis: Statistical package for the social science (SPSS version 20) is used for statistical analysis of data, as it contains the test of significance given in standard statistical books. Collected data was summarized and tabulated by using descriptive and inferential statistics.

\section{Results}

Results of the study are presented in two major sections.

Section I: Demographic and medical data

The first section is includes two parts a) presents description of the statistical analysis of demographic data. Part b) presents description of the statistical analysis of medical data which collected through demographic and medical data questioner, this tool is consisted of two parts First part include: demographic data covering questions such as age, gender, level of education, and occupation. The second part: medical data sheet which includes questions related to medical diagnosis, surgical operation, duration of operation, .....etc ..

Table (1), the study sample is consisted of 30 subjects for each control and study group. The mean age of the control and the study group is $(42.73 \pm 9.91)(37.43 \pm 11.29)$ years respectively. $(60 \%)$ of the control group and $(60.7 \%)$ of the study group are female. (36.7\%) of the control group can read and write and $(36.7 \%)$ has elementary and secondary education while the study subject has $(40 \%)$ can read and write and $(43.3 \%)$ has elementary and secondary education. The occupation of the studied subject is $(46.7 \%)$ of the control group and 
$(43.3 \%)$ of the study group are house wife. (70\%) of the control group and $(56.7 \%)$ of the study subject comes from city. There are no statistical significant differences among the two groups regarding all demographic characteristics.

Table (1) Frequency and percentage distribution of demographic data among the studied patients $(\mathrm{n}=60)$.

\begin{tabular}{|c|c|c|c|c|}
\hline & \multicolumn{2}{|c|}{$\begin{array}{l}\text { Control group } \\
(\mathrm{N}=30)\end{array}$} & \multicolumn{2}{|c|}{$\begin{array}{l}\text { Study group } \\
(\mathrm{N}=30)\end{array}$} \\
\hline & \multicolumn{2}{|l|}{ No } & \multicolumn{2}{|l|}{ No } \\
\hline \multicolumn{5}{|l|}{ Age } \\
\hline $20 \leq 30$ & 2 & 6.6 & 9 & 30 \\
\hline $31 \leq 40$ & 12 & 40 & 8 & 26.7 \\
\hline $41 \leq 50$ & 8 & 26.7 & 9 & 30 \\
\hline $51 \leq 60$ & 8 & 26.7 & 4 & 13.3 \\
\hline$($ Mean \pm SD $)$ & \multicolumn{2}{|c|}{$(42.73 \pm 9.91)$} & \multicolumn{2}{|c|}{$(37.43 \pm 11.29)$} \\
\hline \multicolumn{5}{|l|}{ Gender } \\
\hline Male & 12 & 40 & 10 & 33.3 \\
\hline Female & 18 & 60 & 20 & 66.7 \\
\hline \multicolumn{5}{|l|}{ Education } \\
\hline Can't read and write & 4 & 13.3 & 2 & 6.7 \\
\hline Read and write & 11 & 36.7 & 12 & 40 \\
\hline Middle education & 11 & 36.7 & 13 & 43.3 \\
\hline Bachelor education & 4 & 13.3 & 3 & 10 \\
\hline \multicolumn{5}{|l|}{ Occupation } \\
\hline Not work & 0 & 0 & 2 & 6.7 \\
\hline House wife & 14 & 46.7 & 13 & 43.3 \\
\hline Worker & 9 & 30 & 9 & 30 \\
\hline Worked in office & 7 & 23.3 & 6 & 20 \\
\hline \multicolumn{5}{|l|}{ Place of residence } \\
\hline Rural & 9 & 30 & 13 & 43.3 \\
\hline City & 21 & 70 & 17 & 56.7 \\
\hline
\end{tabular}

Table (2) presents that (50\%) of the control group and $(36.7 \%)$ of the study subject has umbilical hernia and cholecystitis is $(6.7 \%)$ and $(10 \%)$ for control and study group respectively. Seventy three point three of each control and study group performed mesh repair surgery. (43.3\%) of the control group and (50\%) of the study group has weight ranging between $71 \mathrm{Kg}$ to less than $90 \mathrm{Kg}$, with the mean weight of $(77.57 \pm 13.642) \mathrm{Kg}$ and (80.20 .12 .452$) \mathrm{Kg}$ for control and study group respectively. The two hours duration of operation is about $(63.3 \%)$ subject for the control group and $(73.3 \%)$ subject for the study group. The subjects that stay in room temperature ranging between $20^{\circ} \mathrm{C}$ to less than $23^{\circ} \mathrm{C}$ presents about $(63.3 \%)$ for the control group and $(56.7 \%)$

Table (2) Frequency and percentage distribution of the medical background data among the study subjects

\begin{tabular}{|c|c|c|c|c|}
\hline & \multicolumn{2}{|r|}{ Control group } & \multicolumn{2}{|r|}{ Study group } \\
\hline & $\mathrm{NO}$ & $\%$ & NO & $\%$ \\
\hline \multicolumn{5}{|l|}{ Medical diagnosis } \\
\hline Umbilical hernia & 15 & 50 & 11 & 36.7 \\
\hline Para umbilical hernia & 3 & 10 & 4 & 23.3 \\
\hline Incisional hernia & 5 & 16.7 & 4 & 13.3 \\
\hline Epigastric hernia & 4 & 13.3 & 0 & 0 \\
\hline Femoral hernia & 1 & 1 & 4 & 13.3 \\
\hline Hiatus hernia & 0 & 0 & 1 & 3.3 \\
\hline Cholecystitis & 2 & 6.7 & 3 & 10 \\
\hline \multicolumn{5}{|l|}{ Body weight by KG } \\
\hline $57 \leq 70$ & 11 & 36.7 & 8 & 26.7 \\
\hline $71 \leq 90$ & 13 & 43.3 & 15 & 50 \\
\hline $91 \leq 108$ & 6 & 20 & 7 & 23.3 \\
\hline$($ Mean \pm SD) & & $(77.57 \pm 13.642)$ & $(80.20$ & \\
\hline \multicolumn{5}{|l|}{ Surgical operation } \\
\hline Mesh repair & 22 & 73.3 & 22 & 73.3 \\
\hline Hernioraphy & 6 & 20 & 5 & 16.7 \\
\hline Open cholecystectomy & 2 & 6.7 & 3 & 10 \\
\hline \multicolumn{5}{|l|}{ Duration of operation } \\
\hline One hour & 1 & 3.3 & 1 & 3.3 \\
\hline One and half hour & 10 & 33.3 & 7 & 23.3 \\
\hline Two hour & 19 & 63.3 & 22 & 73.3 \\
\hline$($ Mean \pm SD) & & $(1.80 \pm .281)$ & $(1.851$ & \\
\hline
\end{tabular}




\begin{tabular}{|l|l|l|l|l|}
\hline Room temperature & 21 & 63.3 & 17 & 56.7 \\
\hline $20 \leq 23$ & 9 & 36.7 & 13 & 43.3 \\
\hline $24 \leq 27$ & \multicolumn{5}{|l|}{$(22.53 \pm 1.655)$} & $(23.23 \pm 2.063)$ \\
\hline (Mean \pm SD) & \multicolumn{5}{|l|}{} \\
\hline
\end{tabular}

\section{Section II:}

This section is consists of two parts first part is devoted to description of the statistical analysis of perioperative temperature measurements, second part presents shivering assessment using Bedside Shivering Assessment Scale (BSAS) and wound infection assessment using ASEPSIS wound infection scoring system.

Table(3-a) shows that (33.3\%) of the control group and (40\%) of the study group preoperative temperature ranging between $36.0^{\circ} \mathrm{C}$ to less than $36.5^{\circ} \mathrm{C}$ which are more risky for intraoperative hypothermia. There is no statistical significant difference between control group and study group in the preoperative temperature readings as $(\mathrm{t}=1.298 \mathrm{p}=.200)$ and mean temperature $(36.7 \pm .504){ }^{\circ} \mathrm{C}(36.56 \pm .381)^{\circ} \mathrm{C}$ for control and study group respectively.

Table (3-a) Frequency and Percentage Distribution of Patient Preoperative Body Temperature Reading among Study Subjects $(\mathrm{N}=60)$ :

\begin{tabular}{|c|c|c|c|}
\hline Preoperative temperature & $\begin{array}{c}\text { Control group } \\
(\mathrm{N}=30)\end{array}$ & $\begin{array}{c}\text { Study group } \\
\quad(\mathrm{N}=30)\end{array}$ & T test $p$ (value) \\
\hline & No & No & \\
\hline $\begin{array}{cc}- & 36.0 \leq 36.4^{\circ} \mathrm{C} \\
- & 36.5 \leq 37.5^{\circ} \mathrm{C} \\
(\text { Mean } \pm \mathrm{SD}) & \end{array}$ & $\begin{array}{lr}10 & 33.3 \\
20 & 66.7 \\
(36.7 \pm .504)\end{array}$ & $\begin{array}{lc}12 & 40 \\
18 & 60 \\
(36.56 \pm .381)\end{array}$ & $\begin{array}{l}\mathrm{t}=1.298 \\
\mathrm{p}=.200 \\
(\mathrm{NS})\end{array}$ \\
\hline
\end{tabular}

*Significant $<0.05 * *$ highly significance *significance $(\mathrm{NS})$ : not significant

Table (3-b) presents intraoperative temperature assessment of the control and study group which presents that there is gradual reduction in control subjects temperature as $(36.7 \%)$ of first, $(66.7 \%)$ of second, (70\%) of third and $(56.7 \%)$ of forth temperature assessment ranging between $34.1^{\circ} \mathrm{C}$ to less than $35.9^{\circ} \mathrm{C}$ which indicate the occurrence of intraoperative hypothermia in the control group. But intraoperative temperature assessment of the study group presents that (13.3\% ) of first, $(23.3 \%)$ of the second , $(16.7 \%)$ of the third and (16.7\%) of the forth assessment temperature ranging between $34.1^{\circ} \mathrm{C}$ to less than $35.9^{\circ} \mathrm{C}$ which indicate the less occurrence of intraoperative hypothermia in the study group. Also the mean of intraoperative temperature

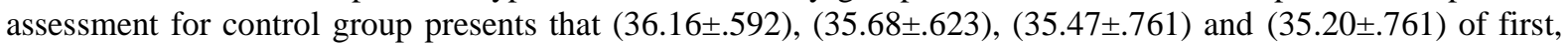
second, third, and fourth assessment respectively. But the mean of intraoperative temperature assessment for study group presents that $(36.33 \pm .402)^{\circ} \mathrm{C},(36.33 \pm .404){ }^{\circ} \mathrm{C},(36.33 \pm .499){ }^{\circ} \mathrm{C}$, and $(36.3 \pm .489){ }^{\circ} \mathrm{C}$ of first, second, third, and fourth assessment respectively

Table (3-b) Frequency and Percentage Distribution of Patient Intraoperative Body Temperature Readings among Study Subjects $(\mathrm{N}=60)$ :

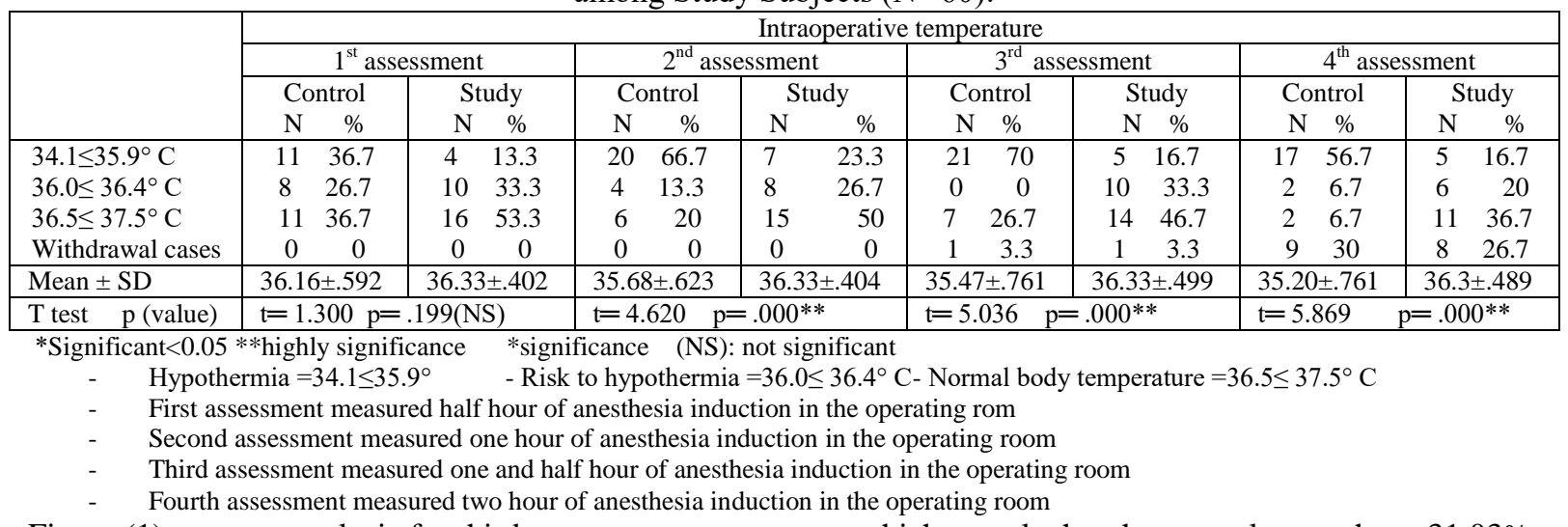

Figure (1) presents analysis for third temperature assessment which reveals that the control group have $31.03 \%$, $24.14 \%$, and $17.24 \%$, complain from sever, moderate, mild hypothermia respectively. Patients have normal body temperature in control group are $27.59 \%$. While in the study group patients complain from moderate and mild hypothermic are $6.9 \%$ and $10.34 \%$ respectively. Patients have normal body temperature in study group are $82.76 \%$. 
Figure (1) Temperature Assessment Analysis for Third Temperature Assessment in the Control and Study Group $(\mathrm{N}=58)$
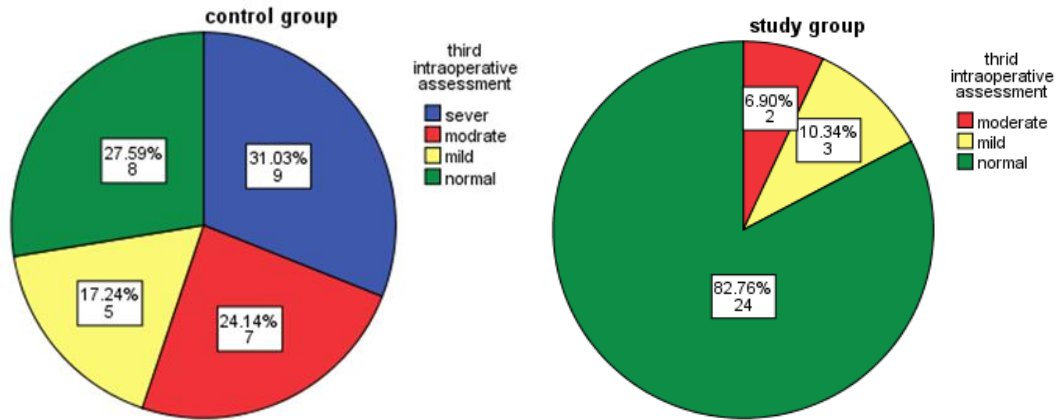

Note: sever hypothermia $\leq 34.9^{\circ} \mathrm{C}$, moderate hypothermia $35.0 \leq 35.4^{\circ} \mathrm{C}$, mild hypothermia $35.5 \leq 30.9^{\circ} \mathrm{C}$, and normal temperature $36.0 \leq 37.5$

Table (3-c) shows recovery temperature assessment which presents $(63.3 \%)$ of the control group and (3.3\%) the study group temperature assessment ranging between $34.1^{\circ} \mathrm{C}$ to less than $35.9^{\circ} \mathrm{C}$ which indicate the study (warmed intra operatively) group less occurrence of hypothermia than control group, also the mean temperature of recovery measurement is $(35.76 \pm .633)^{\circ} \mathrm{C},(36.70 \pm .378){ }^{\circ} \mathrm{C}$ for control and study group respectively. there are high statistical significant differences between control group and study group in the recovery temperature reading $(\mathrm{t}=7.027 \mathrm{p}=.000)$.

Table (3-c) Frequency and Percentage Distribution of Patient recovery Body Temperature Reading among Study Subjects $(\mathrm{N}=60)$ :

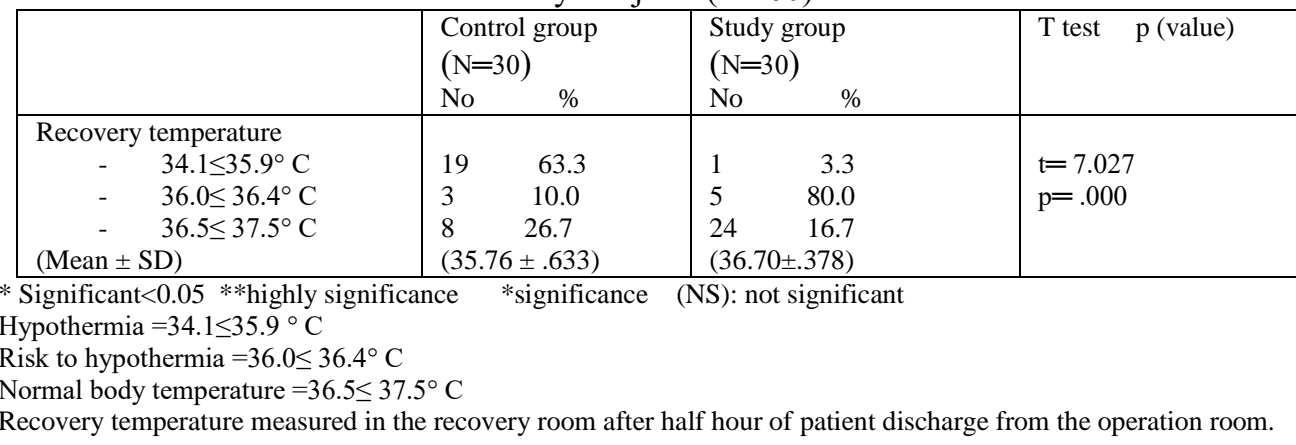

Table (4) clarifies that occurrence of post anesthesia shivering which include mild (20\%), moderate (10\%) in the control group and mild $(6.7 \%)$ in the study group. There are statistical significant differences between control group and study group in the incidence of post anesthesia shivering $(t=2.533 p=.016)$.

Table (4): Frequency and Percentage of Bedside Shivering Assessment Scale Score in the Recovery Room among Study Subjects $(\mathrm{N}=60)$.

\begin{tabular}{|c|c|c|c|c|c|}
\hline \multirow[t]{2}{*}{ Variable } & \multicolumn{2}{|c|}{ Control Group } & \multicolumn{2}{|c|}{ Study Group } & \multirow{2}{*}{$\begin{array}{l}\mathrm{T} \text { test } \\
\mathrm{p} \text { (value) }\end{array}$} \\
\hline & frequency & $\%$ & frequency & $\%$ & \\
\hline $\begin{array}{cl}\text { Bedside } & \text { Shivering Assessment Scale Score } \\
- & \text { none } \\
- & \text { mild } \\
- & \text { moderate } \\
- & \text { sever }\end{array}$ & $\begin{array}{l}21 \\
6 \\
3 \\
0\end{array}$ & $\begin{array}{l}70.0 \\
20.0 \\
10.0 \\
0.0\end{array}$ & $\begin{array}{l}28 \\
2 \\
0 \\
0\end{array}$ & $\begin{array}{l}93.3 \\
6.7 \\
0.0 \\
0.0\end{array}$ & $\begin{array}{l}\mathrm{t}=2.533 \\
\mathrm{p}=.016^{*}\end{array}$ \\
\hline
\end{tabular}

* Significant $<0.05 * *$ highly significance $\quad *$ significance $(\mathrm{NS})$ : not significant

None: No Shivering

Mild: Shivering localized to neck/thorax, may be seen only as artifact on ECG or felt by Palpation

Moderate: Intermittent involvement of the upper extremities $+/$ - thorax

Severe: Generalized shivering or sustained upper, lower extremity shivering

Table (5) revealed that (30\%) of control group and (13.3\%) of study group have disturbance of healing, $(6.7 \%)$ of control group and $(3.3 \%)$ of study group have minor wound infection and $(10.0 \%)$ of control group and $(3.3 \%)$ of study group have moderate wound infection. there are statistical significant differences between control group and study group in the incidence of surgical site infection $(\mathrm{t}=2.165 \mathrm{P}=.035)$.. 
Table (5): Frequency, Percentage of ASEPSIS Wound Infection Score among Study Subjects ( $\mathrm{N}=60$ ).

\begin{tabular}{|c|c|c|c|c|c|c|}
\hline \multirow{2}{*}{\multicolumn{2}{|c|}{ ASEPSIS wound infection score }} & \multicolumn{2}{|c|}{ Control Group } & \multicolumn{2}{|c|}{ Study Group } & \multirow[t]{2}{*}{ T test $\mathrm{p}$ (value) } \\
\hline & & Frequency & $\%$ & Frequency & $\%$ & \\
\hline- & Satisfactory healing & 16 & 53.3 & 24 & 80.0 & \multirow{5}{*}{$\begin{array}{l}\mathrm{t}=2.165 \\
\mathrm{p}=.035^{*}\end{array}$} \\
\hline- & Disturbance of healing & 9 & 30.0 & 4 & 13.3 & \\
\hline- & Minor wound infection & 2 & 6.7 & 1 & 3.3 & \\
\hline- & Moderate wound infection & 3 & 10.0 & 1 & 3.3 & \\
\hline- & Sever wound infection & 0 & 0 & 0 & 0 & \\
\hline
\end{tabular}

* Significant $<0.05 * *$ highly significance $\quad *$ significance $(\mathrm{NS})$ : not significant

Satisfactory healing $(0 \leq 10)$

Disturbance of healing $(11 \leq 20)$

Minor wound infection $(21 \leq 30)$

Moderate wound infection $(31 \leq 40)$

Sever wound infection $(>40)$

Table (6) presents that there are significant negative correlation occur between incidence of surgical site infection and intraoperative temperature readings; first assessment $\left(\mathrm{r}=-.615^{* *}\right)$, second assessment $(\mathrm{r}=$ $\left..741^{* *}\right)$, third assessment $\left(\mathrm{r}=-.628^{* *}\right)$, and fourth assessment $(\mathrm{r}=-.564 * *)$ among study group. There are significant negative correlation occur between incidence of surgical site infection and recovery temperature; $(\mathrm{r}=$ $-.524 * *)$ for control group, and $(1=-.636 * *)$ for study group.

Table (6): Correlation between ASEPSIS Wound Infection Score and Temperature Reading among Study Subjects $(\mathrm{N}=60)$.

\begin{tabular}{|c|c|c|c|c|c|c|c|}
\hline \multirow{3}{*}{\multicolumn{2}{|c|}{ ASEPSIS wound score }} & \multicolumn{6}{|c|}{ Temperature Reading } \\
\hline & & \multirow{2}{*}{$\begin{array}{l}\text { Preoperative } \\
\text { temperature }\end{array}$} & \multicolumn{4}{|c|}{ Intraoperative temperature } & \multirow{2}{*}{$\begin{array}{c}\text { Recovery } \\
\text { temperature }\end{array}$} \\
\hline & & & $1^{\text {st }}$ assess & $2^{\text {nd }}$ assess & $3^{\text {rd }}$ assess & $4^{\text {th }}$ assess & \\
\hline & $\begin{array}{l}\text { Control } \\
\text { Group }\end{array}$ & $\mathrm{r}=-.201$ & $\mathrm{r}=-.328^{*}$ & $\mathrm{r}=-.427 *$ & $\mathrm{r}=-.564 * *$ & $\mathrm{r}=-.675^{* *}$ & $\mathrm{r}=-.524 * *$ \\
\hline- & Study Group & $\mathrm{r}=-.391 *$ & $\mathrm{r}=-.615 * *$ & $\mathrm{r}=-.741 * *$ & $\mathrm{r}=-.628 * *$ & $\mathrm{r}=-.564 * *$ & $\mathrm{r}=-.636 * *$ \\
\hline
\end{tabular}

*. Correlation is significant at the 0.05 level (2-tailed).

**. Correlation is significant at the 0.01 level (2-tailed).

\section{Discussion}

Intraoperative hypothermia, defined as core temperature $<36^{\circ} \mathrm{C}$ during operation, is a common problem among surgical patients [10]. [11]Affirmed that occurrence of perioperative hypothermia up to $90 \%$, more recently [12] and [13] was recorded that the incidence of intraoperative hypothermia is about $4 \%$ to $72 \%$. Many professional associations, such as the Association of periOperative Registered Nurses (AORN), and the National Institute for Health and Care Excellence (NICE) have made recommendations for preventing hypothermia and improving its management during the perioperative period. Despite its significance, little information is available about intraoperative hypothermia, its complication, and its management. So this study conducted to evaluate the impact of induced normothermia on occurrence of post anesthetic shivering and wound infection among patients undergoing abdominal surgeries.

The study subject' age range between $(20 \leq 60$ years $)$ with mean age $(42.73 \pm 9.91)$ among the control group, and (37.43 \pm 11.29$)$ among the study group, so hypothermia can occur at any age. In the same line with study entitled "Occurrence and factors associated with hypothermia during surgery elective abdominal surgery" the sample subject age was ranged between ( $18 \leq 65$ years) [14]. Regarding sex it was found that sixty present of the control group, and $60.7 \%$ of the study group are female. And this is agreed with [15] study sample as $60 \%$ of their sample was female.

On the subject of medical background data, the majority of the study sample diagnosed with hernia as (93.3\%) of the control group and (90\%) of the study group had hernia and the rest had cholecystitis on the same line [16]. carried out study on ventral hernia and they submitted Five hundred fifty-three patients were included and hypothermic patient was $29 \%$ with mean temperature $\left(35.7^{\circ} \mathrm{C} \pm 1.3^{\circ} \mathrm{C}\right)$. Also [14] study sample of patient undergoing abdominal surgery and they found that $78(85.7 \%)$ patients were hypothermic with average temperature of $35.2^{\circ} \mathrm{C}$ at the end of surgery.

As regard to the duration of operation; patients stayed in the operation two hours was (63.3\%) among the control group with mean $(1.80 \pm .281)$ and $(73.3 \%)$ among the study group with mean (1.851 .267$)$. [17] stated that any patient undergoing surgical intervention more than 30 minute should be warmed.

Concerning body weight of the study subject, $(43.3 \%)$ of the control group and $(50 \%)$ of the study

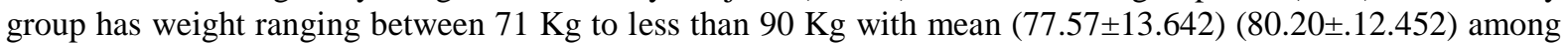


control and study group respectively. In accordance with [18] they reported that body weight is an important factor that has effect on patient body temperature .

As regard to operating room temperature, the current study presents that the study subject stayed in operating room temperature ranging between $20^{\circ} \mathrm{C}$ to less than $23^{\circ} \mathrm{C}$ was $(63.3 \%)$ and (56.7\%) among control and study group respectively. The mean temperature of the operating room is $(22.53 \pm 1.655)$ and $(23.23 \pm 2.063)$ among control and study group respectively, this is matched with the ASPAN's Evidence-Based Clinical Practice Guideline for the Promotion of Perioperative Normothermia[19] stated that the operating room temperature should be not less than $21^{\circ} \mathrm{C}$.

The preoperative temperature assessed while patient waiting the surgery $(33.3 \%)$ of the control group and $(40 \%)$ of the study group preoperative temperature ranging between $36.0^{\circ} \mathrm{C}$ to less than $36.5^{\circ} \mathrm{C}$ on the same way [20]. revealed that their study subject had mean temperature $(36.3 \pm 0.7){ }^{\circ} \mathrm{C}$ on arrival to the operating room.

After half hour of anesthesia induction $36.7 \%$ of the control group become hypothermic $\left(34.1^{\circ} \mathrm{C}\right.$ $\left.\leq 35.9^{\circ} \mathrm{C}\right)$, with mean $\left(36.16^{\circ} \mathrm{C} \pm 592^{\circ} \mathrm{C}\right)$. and after one hour $66.7 \%$ of the control group become hypothermic $\left(34.1^{\circ} \mathrm{C} \leq 335.9^{\circ} \mathrm{C}\right)$ with mean $\left(35.68^{\circ} \mathrm{C} \pm 623^{\circ} \mathrm{C}\right)$ in consistent with [21] which found that the mean temperature after 30 minutes in the control groups was $36.1{ }^{\circ} \mathrm{C}$ and the mean temperature after 1 hour in the control groups was $35.9{ }^{\circ} \mathrm{C}$. And also [22] explained that hypothermia occurred during first hour of anesthesia induction due to many reasons .

After 90 minute of anesthesia induction $70 \%$ of control group complain from hypothermia $\left(34.1^{\circ} \mathrm{C}\right.$ $\left.\leq 35.9^{\circ} \mathrm{C}\right)$ with mean $\left(35.47^{\circ} \mathrm{C} \pm .761^{\circ} \mathrm{C}\right)$. and after 120 minute of anesthesia induction, there are $9(30.0 \%)$ cases finished their operation before two hours so the fourth assessment not taken to them and $56.7 \%$ become hypothermic $\left(34.1^{\circ} \mathrm{C} \leq 35.9^{\circ} \mathrm{C}\right)$ with mean $\left(35.2^{\circ} \mathrm{C} \pm .76^{\circ} \mathrm{C}\right)$. In line with [23]report that core temperature in the control group decreased to $35.5^{\circ} \mathrm{C}$ with standard deviation of $0.3^{\circ} \mathrm{C}$ during the first 3 hours after anesthesia induction. [24] a literature review recorded that up to $70 \%$ of surgical patients develop hypothermia perioperatively

Temperature assessment analysis of temperature measured after 90 minutes of anesthesia induction revealed that the control group had $31.03 \%, 24.14 \%$, and $17.24 \%$ complained from sever $\left(<35.0^{\circ} \mathrm{C}\right)$, moderate $\left(35.0-35.4^{\circ} \mathrm{C}\right)$, mild hypothermia $\left(35.5-35.9^{\circ} \mathrm{C}\right)$ respectively. Patients had normal body temperature in control group are $27.59 \%$. While in the study group patients complained from moderate and mild hypothermic was $6.9 \%$ and $10.34 \%$ respectively. Patients had normal body temperature in study group was $82.76 \%$. On the same vein [25] stated that among 1,409 patients, 528 (37.5\%) had hypothermia, which was classified as mild (35.5$\left.35.9^{\circ} \mathrm{C}\right)$ in 358 , moderate $\left(35.0-35.4^{\circ} \mathrm{C}\right)$ in 137 , and severe $\left(<35.0^{\circ} \mathrm{C}\right)$ in 33 .

The use of warm fluid is effective in keeping patient normothermic during the intraoperative period in operation less than two hours. There are high statistical significant differences between control group and study group in the intraoperative temperature assessment as the $\mathrm{p}$ value is $(t=4.620 \mathrm{p}=.000)$ after one hour of anesthesia induction, $(\mathrm{t}=5.036 \mathrm{p}=.000)$ after one and half hour of anesthesia induction and $(\mathrm{t}=5.869$ $\mathrm{p}=.000$ ) after two hours of anesthesia induction. Also the mean intraoperative temperature after two hours of the anesthesia induction is $\left(35.20^{\circ} \mathrm{C} \pm .76\right)$ and $\left(36.3^{\circ} \mathrm{C} \pm .489\right)$ among control and study group respectively. There are many studies support this research result as [26] they found that warmed intravenous fluids kept people significantly warmer than un warmed intravenous fluids at 30, 60, 90 and 120 minutes after induction of anesthesia with $\mathrm{P}$ value $=0.06$. In addition to [27] stated that used intraopertive fluid should be warmed to at least $37^{\circ} \mathrm{C}$. Also [28] explained that warming infusion solutions in an infusion warmer ("in-line warming") is very effective and should be applied.

[23]Explained that in the study group, core temperature decreased during the first 60 minutes, but increased to $36.9 \pm 0.3^{\circ} \mathrm{C}$ at the end of anesthesia. Infusion of warm fluid is effective in keeping patients nearly normothermic. [29] stressed that all intravenous fluids should be warmed before administration to reduce the occurrence of intraoperative hypothermia. [30] explained that the mean of' core body temperature at the end of anesthesia in the study and control groups were $36 \pm 0.5^{\circ} \mathrm{C}$ and $35.34 \pm 0.6^{\circ} \mathrm{C}$, respectively $(\mathrm{P}<0.05)$.

In the recovery room there was $63.3 \%$ of the control group became hypothermic $\left(34.1^{\circ} \mathrm{C} \leq 35.9^{\circ} \mathrm{C}\right)$ with mean $(35.76 \pm .633)^{\circ} \mathrm{C}$. In the same way [31] review of literature presented that in the recovery room, $26 \%$ to $90 \%$ of all post anesthesia patients complain from hypothermia in patients who have undergone elective surgery. [32] Found that hypothermia at post anesthesia care unit was 32\% .

Only $3.3 \%$ of the study (warmed) group was hypothermic in the recovery room with mean (36.70 \pm .378$)$ and there was significant statistical difference between study and control group in the recovery patient temperature as $(\mathrm{t}=7.027 \mathrm{p}=.000)$. In accordance with [33] reported that warmed patient have less incidence of post anesthesia hypothermia $\left(<36^{\circ} \mathrm{C}\right)$ on the recovery room with $\mathrm{p}=0.039$.

The current study reports that occurrence of post anesthesia shivering is $30 \%$ for the control group and there are many studies agreed with this result as [34] found the incidence of postoperative shivering was $30 \%$. 
Also [35] found that 32\% of the control group showed post anesthesia shivering. In addition to [36] explained that post anesthesia shivering incidence rate in the control group was $47.5 \%$.

The current study turn on that occurrence of post anesthesia shivering includes mild (20\%), moderate (10\%) among the control group and mild (6.7\%) among the study group. there are statistical significant differences between control group and study group in occurrence of post anesthesia shivering $(t=2.533 p=$ .016). [33] on study titled "Effect of pre-0warmed intravenous fluids on perioperative hypothermia and shivering after ambulatory surgery under monitored anesthesia care" stated that the warmed patient have less occurrence post anesthesia shivering with $\mathrm{p}=0.039$. [37] explained that post anesthesia shivering is mainly caused by perioperative hypothermia.

The incidence of wound infection in the control group presents that (30\%) have disturbance of healing, $(6.7 \%)$ have minor wound infection and $(10.0 \%)$ have moderate wound infection. In the same vein a large scale survey was conducted to examine risk factors for surgical site infections (SSIs) among Japanese patients undergoing gastrointestinal surgery. SSIs were identified in 1471 of 12015 available cases, with an overall incidence of $12.2 \%$ [38].

The current study revealed that $16.7 \%$ among the control group have wound infection and $6.7 \%$ among study group have wound infection. There are statistical significant differences between control group and study group in the incidence of surgical site infection $(t=2.165 \mathrm{p}=.035)$, so that the study (warmed) group have less occurrence and severity of surgical wound infection. [39] reported that multivariate analysis determined that a single intraoperative temperature measurement less than $35^{\circ} \mathrm{C}$ independently increased the site infection risk $221 \%$ per degree below $35^{\circ} \mathrm{C}$ (OR: $2.21 ; 95 \%$ CI: $\left.1.24-3.92, \mathrm{P}=0.007\right)$. In the same way [25] submitted that sever intraoperative hypothermia increase incidence and severity of surgical wound infection.

The current study presents that there are significant negative correlation occur between incidence of surgical site infection and intraoperative temperature readings as among study group $\left(\mathrm{r}=-.615^{* *}\right),\left(\mathrm{r}=-.741^{* *}\right)$, $\left(\mathrm{r}=-.628^{* *}\right),(\mathrm{r}=-.564 * *)$ of first, second, third, and fourth assessment respectively , this in accordance with [40] carried out review of literature titled "Thermoregulation and risk of surgical site infection" they explained that intraoperative hypothermia increase surgical site infection incidence.

Briefly, the mean temperature before anesthesia induction is $(36.7 \pm .504)$ and after half hour is (36.1 $\pm .592)$ so there are drop $.5^{\circ} \mathrm{C}$ from body temperature after half hour of anesthesia induction. The mean temperature is $(36.1 \pm .592),(35.68 \pm .623),(35.47 \pm .761)$, and $(35.20 \pm .761)$ after half, one, one and half, and after two hour of anesthesia induction respectively which demonstrate progress of intraoperative hypothermia. (70\%) of control group was hypothermic after 90 minutes. the use of warm fluid is effective in keeping patient normothermic during the intraoperative period in operation less than two hours under controlled room temperature as the $\mathrm{p}$ value was $(\mathrm{p}=.000)$ after one hour of anesthesia induction, $(\mathrm{p}=.000)$ after 90 minute of anesthesia induction and $(\mathrm{p}=.000)$ after 120 minute of anesthesia induction .Occurrence of hypothermia in the recovery room is $63.3 \%$ from the control group as their temperature less than $36.0^{\circ} \mathrm{C}$ and warmed patient have less incidence of hypothermia in the recovery room as $3.3 \%$ from the study group their temperature less than $36.0^{\circ} \mathrm{C}$.

\section{Conclusion}

Patients undergoing abdominal surgery are at high risk to develop perioperative hypothermia which enhances many complication including post anesthesia shivering and surgical site infection. Using of warm fluids in the operating room control and prevents intraoperative hypothermia in operations less than two hours under controlled room temperature.

\section{Nursing Implications And Recommendations}

In the light of the findings of the present study, the following are recommended:

1. Patient's education about perioperative hypothermia, passive method of warming and its complications is very important aspect on perioperative hypothermia management.

2. It is important to set rules that regulating operating room temperature according to standard average .

3. Support the operating rooms with active methods and devices of patient warming.

4. Planning educational programs about perioperative hypothermia, it's complication and it's management for health staff

5. Perioperative and perianesthesia nurse's education about perioperative hypothermia and its complications is very important aspect on perioperative hypothermia management.

6. Perioperative and perianesthesia nurse's education about passive and active methods of preoperative, intraoperative and postoperative hypothermia management.

7. Perioperative and perianesthesia nurse's education about important of patient body temperature monitoring.

8. Nurse's education about importance of patient education about perioperative hypothermia . 
9. Replication of the study on larger probability sample selected from different geographical areas in Egypt is recommended to obtain more generalizable data.

10. Implementation of studies which assess the adherence to settled guidelines related to perioperative hypothermia management in Egypt.

11. Implementation of studies that assess incidence of perioperative hypothermia and its risk factors on large sample from different health organization in Egypt.

12. Carry out studies related to perioperative hypothermia complications.

13. Carry out studies related to available used methods and devices of warming in the perioperative period and its effectiveness.

14. Carry out study related to health staff awareness about unplanned perioperative hypothermia

\section{References}

[1] Roberson, M., Dieckmann, L., Rodriguez, R., \& Austin, P. (2013). A review of the evidence for active preoperative warming of adults undergoing general anesthesia. AANA J, 81(5), 351-62.

[2] Stannard,D.\& krenzischek,D.A., (2012).Perianesthsia nursing care :A bedside care for safe recovery.Jones\&Barylett learning Canada 6339 Ormindale way Mississauga.ontarrio L5v Ij2 Canada: Kevin sullivan $(55,56)$.

[3] Díaz, M., \& Becker, D. (2010). Thermoregulation: physiological and clinical considerations during sedation and general anesthesia. Anesthesia progress,57(1), 25- 33.

[4] Fettes, S., Mulvaine, M., \& Van Doren, E. (2013). Effect of preoperative forced-air warming on postoperative temperature and postanesthesia care unit length of stay. Association of PeriOperative Registered Nurses Journal, 97(3), 323-328.

[5] Andrzejowski, J., Turnbull, D., Nandakumar, A., Gowthaman, S., \& Eapen, G. (2010). A randomised single blinded study of the administration of pre-warmed fluid vs active fluid warming on the incidence of peri- operative hypothermia in short surgical procedures*. Anaesthesia, 65(9), 942-945.

[6] Burns, S., Wojnakowski, M., Piotrowski, K., \& Caraffa, G. (2009). Unintentional hypothermia: implications for perianesthesia nurses. Journal of PeriAnesthesia Nursing, 24(3), 167-176.

[7] Dinardo, J. (2008). Natural experiments and quasi-natural experiments. The New Palgrave Dictionary of Economics,pp: 856-859, doi:10.1057/9780230226203.11629.

[8] Petrica, A., Brinzeu, C., Brinzeu, A., Petrica, R., \& Ionac, M. (2009). Accuracy of surgical wound infection definitions-the first step towards surveillance of surgical site infections. TMJ, 59(3-4), 362-365.

[9] Gottrup, F., Melling, A., \& Hollander, D. A. (2005). An overview of surgical site infections: aetiology, incidence and risk factors. EWMA Journal, 5(2), 11-15.

[10] Forbes SS, Eskicioglu C, Nathens AB, Fenech DS, Laflamme C (2009) Evidence-based guidelines for prevention of perioperative hypothermia. J Am Coll Surg 209: 492-503 e491. doi: 10.1016/j.jamcollsurg.2009.07.002. pmid:19801323

[11] Burger L, Fitzpatrick J (2009) Prevention of inadvertent perioperative hypothermia. Br J Nurs 18: 1114, $1116-1119$. pmid:19966730

[12] eijtens B, Koeter M, Kremers K, Koeter S (2013) High incidence of postoperative hypothermia in total knee and total hip arthroplasty: a prospective observational study. J Arthroplasty 28: 895-898. doi: 10.1016/j.arth.2012.10.006. pmid:23523493

[13] Long KC, Tanner EJ, Frey M, Leitao MM Jr, Levine DA, Gardner DJ, et al. (2013) Intraoperative hypothermia during primary surgical cytoreduction for advanced ovarian cancer: risk factors and associations with postoperative morbidity. Gynecol Oncol 131: 525-530. doi: 10.1016/j.ygyno.2013.08.034. pmid:24016410

[14] Prado, C. B. C., Barichello, E., Pires, P. D. S., Haas, V. J., \& Barbosa, M. H. (2015). Occurrence and factors associated with hypothermia during elective abdominal surgery. Acta Paulista de Enfermagem, 28(5), 475-481.

[15] Denu, A. Z., Semple, P., Tawuye, H. Y., \& Kassa, A. A. (2015). Perioperative Hypothermia and Predictors of Intra-Operative Hypothermia among Patients Operated at Gondar university Hospital from March to April 2015. J Anesth Clin Res, 6(556), 2.

[16] Baucom, R. B., Phillips, S. E., Ehrenfeld, J. M., Holzman, M. D., Nealon, W. H., Sharp, K. W., ... \& Poulose, B. K. (2014). Defining intraoperative hypothermia in ventral hernia repair. journal of surgical research, 190(1), 385-390.

[17] NICE: Clinical-Practice-Guideline, the management of inadvertent perioperative hypothermia in adults. National Collaborating Centre for Nursing and Supportive Care commissioned by National Institute for Health and Clinical Excellence (NICE). http://guidance.nice.org.uk/CG65 (last accessed on 23 January 2015).

[18] Fernandes, L. A., Braz, L. G., Koga, F. A., Kakuda, C. M., Módolo, N. S. P., De Carvalho, L. R., ... \& Braz, J. R. C. (2012). Comparison of peri-operative core temperature in obese and non-obese patients. Anaesthesia, 67(12), 1364-1369.

ASPAN,(2009). "ASPAN's Evidence-Based Clinical Practice Guideline for the Promotion of Perioperative Normothermia", (Volume 24, Issue 5, Page 277, October 2009)

[19] Denu, A. Z., Semple, P., Tawuye, H. Y., \& Kassa, A. A. (2015). Perioperative Hypothermia and Predictors of Intra-Operative Hypothermia among Patients Operated at Gondar university Hospital from March to April 2015. J Anesth Clin Res, 6(556), 2.

[20] Alderson, P., Campbell, G., Smith, A. F., Warttig, S., Nicholson, A., \& Lewis, S. R. (2014). Thermal insulation for preventing inadvertent perioperative hypothermia. The Cochrane Library.

[21] Sessler, D. I. (2016). Perioperative thermoregulation and heat balance. The Lancet, 387(10038), $2655-2664$.

[22] Hong-xia, X., Zhi-jian, Y., Hong, Z., \& Zhiqing, L. (2010). Prevention of hypothermia by infusion of warm fluid during abdominal surgery. Journal of PeriAnesthesia Nursing, 25(6), 366-370.

[23] Knaepel, A. (2012). Inadvertent perioperative hypothermia: a literature review. Journal of perioperative practice, 22(3), 86-90.

[24] Tsuchida, T., Takesue, Y., Ichiki, K., Uede, T., Nakajima, K., Ikeuchi, H., \& Uchino, M. (2016). Influence of peri-operative hypothermia on surgical site infection in prolonged gastroenterological surgery. Surgical infections, 17(5), 570-576. 42. (Tsuchida, et al. (2016))

[25] Campbell, G., Alderson, P., Smith, A., \& Warttig, S. (2015). Warming of intravenous and irrigation fluids for preventing inadvertent perioperative hypothermia. The Cochrane Library.

[26] Jung, K. T., Kim, S. H., So, K. Y., So, H. J., \& Shim, S. B. (2015). Clinical evaluation of a newly designed fluid warming kit on fluid warming and hypothermia during spinal surgery. Korean journal of anesthesiology, 68(5), 462-468.

[27] Horn, Bräuer, Höcker and Wulf, (2014)31 rzejowski, Turnbull, Nandakumar, Gowthaman and Eapen, (2010) 
[28] Choi, J. W., Kim, D. K., Lee, S. W., Park, J. B., \& Lee, G. H. (2016). Efficacy of intravenous fluid warming during goal-directed fluid therapy in patients undergoing laparoscopic colorectal surgery: a randomized controlled trial. Journal of International Medical Research, 44(3), 605-612.

[29] Oshvandi, K., Shiri, F. H., Fazel, M. R., Safari, M., \& Ravari, A. (2014). The effect of pre-warmed intravenous fluids on prevention of intraoperative hypothermia in cesarean section. Iranian journal of nursing and midwifery research, 19(1), 64.

[30] Torossian, A., Bräuer, A., Höcker, J., Bein, B., Wulf, H., \& Horn, E. P. (2015). Preventing inadvertent perioperative hypothermia. Dtsch Arztebl Int, 112(10), 166-72.

[31] Luís, C., Moreno, C., Silva, A., Páscoa, R., \& Abelha, F. (2012). Inadvertent postoperative hypothermia at post-anesthesia care unit: incidence, predictors and outcome.

[32] Kim, G., Kim, M. H., Lee, S. M., Choi, S. J., Shin, Y. H., \& Jeong, H. J. (2014). Effect of pre-warmed intravenous fluids on perioperative hypothermia and shivering after ambulatory surgery under monitored anesthesia care. Journal of anesthesia, 28(6), 880-885

[33] Bhukal, I., Solanki, S. L., Kumar, S., \& Jain, A. (2011). Pre-induction low dose pethidine does not decrease incidence of postoperative shivering in laparoscopic gynecological surgeries. Journal of Anaesthesiology Clinical Pharmacology, 27(3), 349.

[34] Chun, D. H., Kil, H. K., Kim, H. J., Park, C., \& Chung, K. H. (2010). Intrathecal meperidine reduces intraoperative shivering during transurethral prostatectomy in elderly patients. Korean journal of anesthesiology, 59(6), 389-393.

[35] Entezariasl, M., \& Isazadehfar, K. (2013). Dexamethasone for prevention of postoperative shivering: a randomized double-blind comparison with pethidine. International journal of preventive medicine, 4(7), 818 .

[36] Eydi, M., Golzari, S. E., Aghamohammadi, D., Kolahdouzan, K., Safari, S., \& Ostadi, Z. (2014). Postoperative Management of Shivering: A Comparison of Pethidine vs. Ketamine. Anesthesiology and pain medicine, 4(2)

[37] 38 Utsumi, M., Shimizu, J., Miyamoto, A., Umeshita, K., Kobayashi, T., Monden, M., \& Makimoto, K. (2010). Age as an independent risk factor for surgical site infections in a large gastrointestinal surgery cohort in Japan. Journal of Hospital Infection, 75(3), 183-187..

[38] Seamon, M. J., Wobb, J., Gaughan, J. P., Kulp, H., Kamel, I., \& Dempsey, D. T. (2012). The effects of intraoperative hypothermia on surgical site infection: an analysis of 524 trauma laparotomies. Annals of surgery, 255(4), 789-795.

[39] Beltramini, A. M., Salata, R. A., \& Ray, A. J. (2011). Thermoregulation and risk of surgical site infection. Infection control and hospital epidemiology, 32(6), 603-610. 